\title{
Ngày này 20 và 8 năm trước
}

\author{
Vương Quân Hoàng \\ Phenikaa University
}

Hà Nội

Nov. 28, 2021

Cách đây đúng 20 năm, bài hội nghị về phương trình vi phân riêng BlackScholes của tôi đăng trên Kỷ yếu của DEAA 2001 [1]. Đó là bài nghiên cứu ứng dụng tính toán mà tôi viết chương trình tính toán một số công cụ tài chính, trên ngôn ngữ định hướng đối tượng $\mathrm{C}++$ (lúc đó dùng Borland $\mathrm{C}++$ Compiler).

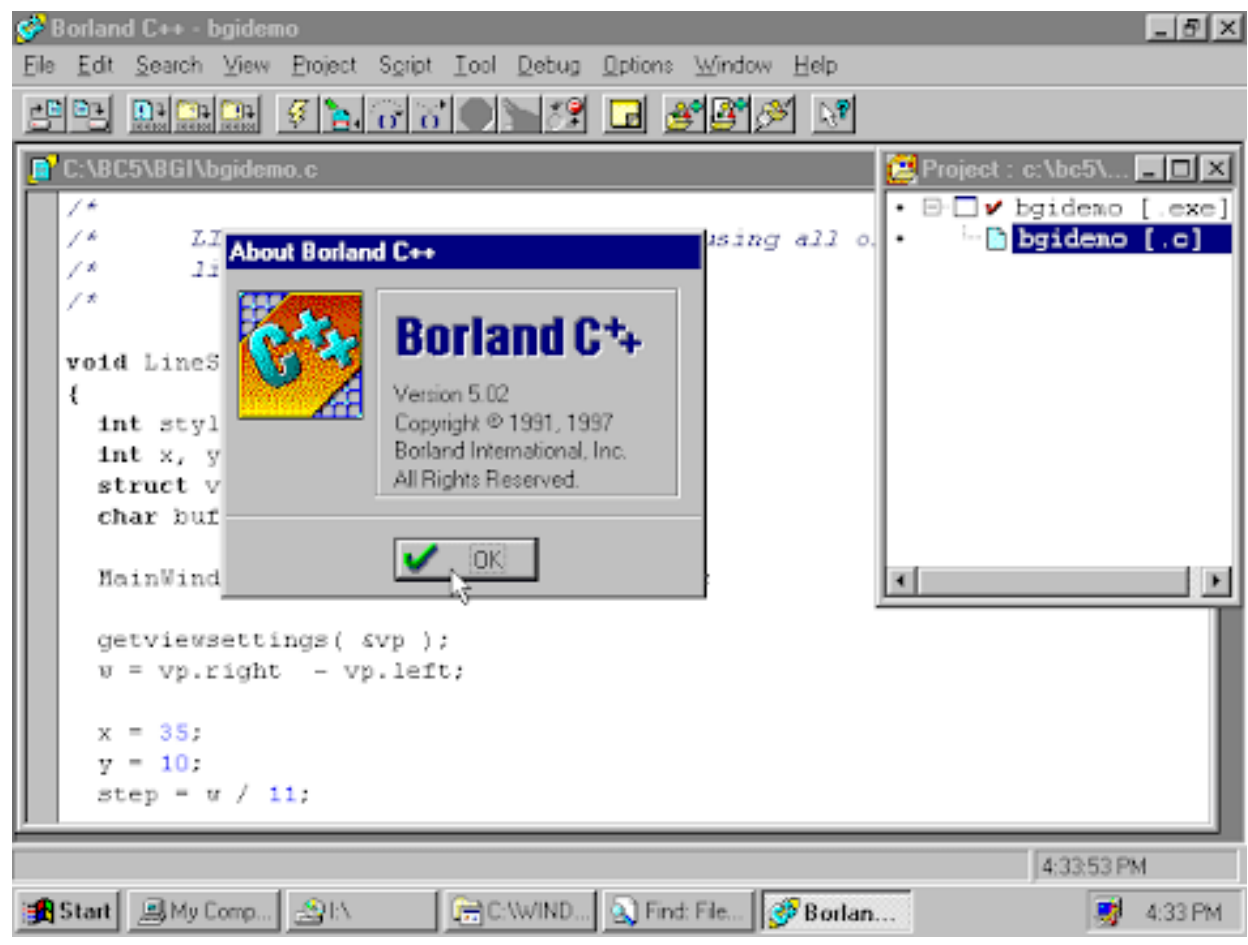

Bài này có sử dụng một ít code mở của Bernt Øksendal trên SourceForge. Lúc đó, việc chia sẻ mã nguồn mở chưa trở nên thông dụng như ngày nay. Hơn nữa, Borland là hãng thương mại, các sách vở kỹ thuật lập trình, nhất là lại có liên quan tới ngành thời thượng financial engineering, luôn đắt tiền. Vì thế, code chương trình viết tốt cũng là tiền.

Vì thế, chỉ riêng việc tìm được một vài routine chạy tốt của $\mathrm{C}++$ cũng là mừng lắm rồi. (Thực ra, nếu tôi nhớ không nhầm thì routine nguồn của Øksendal chạy trên $\mathrm{C}$, nhưng sửa lại chút ít là chạy được tốt trên $\mathrm{C}++$.) 
Kỷ yếu này phát hành cho Hội nghị International Conference on Differential Equations, Approximations and Applications, tổ chức tại Đại học Quốc gia Hà Nội, vào ngày 10-15 tháng 12 năm 2001, gọi tắt DEAA - 2001.

(Tuy nhiên, Kỷ yếu Hội nghị quốc tế luôn được in trước khi Hội nghị diễn ra, và là tài liệu của người tham gia, cho nên cuối tháng 11 là đã sẵn sàng cho sử dụng.)

Một phần bìa Kỷ yếu còn giữ lại trong ảnh dưới đây.

\section{INTERNATIONAL CONFERENCE \\ on \\ DIFFERENTIAL EQUATIONS, \\ APPROXIMATIONS and APPLICATIONS \\ DEAA - 2001 \\ December 10 - 15, 2001}

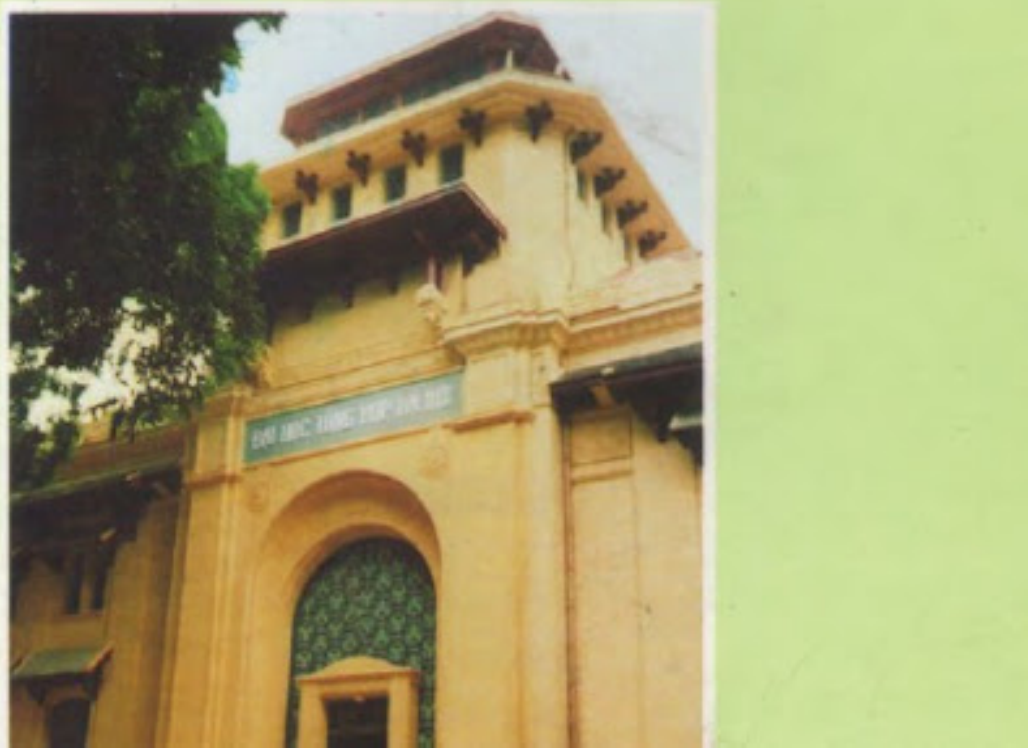

Bì Kỷ yếu DEAA - 2001.

Mới đó mà đã vèo cái 20 năm. Thời gian trôi qua nhanh khủng khiếp!

Gần hơn, thì cùng khoảng thời gian này 8 năm trước, bản thảo về lý thuyết mindsponge hoàn thành, và đang chờ chỉnh sửa để đưa lên Preprint Server của Université Libre de Bruxelles (vẫn có thể truy cập tại đây: https://ideas.repec.org /p/sol/wpaper/2013-153035.html). Tuy thế, phải mất đúng 2 năm sau nữa thì bản thảo này mới vượt qua thẩm định để chính thức xuất bản, tháng 11-2015, cách đây đúng 6 năm [2]. 
Bước vào thời kỳ U60, thì 20, 8 , hay 6 năm đều là những khoảng thời gian dài cả. Đó là vì quỹ thời gian để hoạt động chuyên môn nghiên cứu đang vơi dần, với tốc độ ngày càng nhanh hơn.

\section{References}

[1] Vuong, Q. H. (2001). Black-Scholes PDE: A finance application.

International Conference on Differential Equations, Approximations and Applications, DEAA - 2001 (pg. 53). Vietnam National University, Hanoi.

[2] Vuong, Q. H., \& Napier, N. K. (2015). Acculturation and global mindsponge: an emerging market perspective. International Journal of Intercultural Relations, 49, 354-367. 